\title{
Avaliação da transferência de imunidade passiva em cordeiros com até 30 dias de idade
}

\author{
Passive transfer immunity valuation in lambs with until 30 days of life
}

\author{
Flávia Corbari FÉRES ${ }^{1}$; Adriana Longo LOMBARDI ${ }^{1}$; Tatiana de Sousa BARBOSA ${ }^{1}$; Luiz Cláudio \\ Nogueira MENDES $^{2}$; Juliana Regina PEIRÓ ${ }^{2}$; Fabiano Antonio CADIOLI'; \\ Sílvia Helena Ventruroli PERRI ${ }^{2}$; Francisco Leydson Formiga FEITOSA ${ }^{2}$ \\ ${ }^{1}$ Pós-Graduação em Ciência Animal - Universidade Estadual Paulista, Araçatuba-SP \\ ${ }^{2}$ Curso de Medicina Veterinária da Faculdade de Odontologia da Universidade Estadual Paulista, Araçatuba-SP
}

\begin{abstract}
Resumo
O objetivo deste estudo foi determinar as concentrações séricas de imunoglobulina G, PT e de sua fração eletroforética $\gamma$ globulina, assim como a atividade enzimática de GGT e ALP. Estabeleceu-se a possibilidade da atividade destas enzimas ser utilizada indiretamente como indicadoras de um adequado nível de proteção humoral e/ou como falha de transferência de imunidade passiva em cordeiros. Foi pesquisada a correlação entre as variáveis em quatro grupos de idade divididos em até 30 dias de vida. Para tanto, foram coletadas 191 amostras de sangue de cordeiros em 21 propriedades da região de Araçatuba - São Paulo. Realizaram-se os testes de imunodifusão radial, espectrofotometria e eletroforese para obtenção dos valores de IgG, PT e $\gamma$ globulina, respectivamente. Para os valores da atividade de GGT e ALP, foram utilizados kits comerciais. Notou-se correlação significativa entre ALP e GGT, fato observado também com PT, IgG e GGT. A $\gamma$-globulina mostrou-se correlacionada com GGT, IgG e PT. A atividade de FA não deve ser utilizada como indicadora de transferência de imunidade passiva em cordeiros.
\end{abstract}

Palavras-chave: Fosfatase alcalina. Gama glutamiltrasferase. Imunoglobulina G. Proteína total. $\gamma$ globulina.

\begin{abstract}
The aim of this study was to determine the serum concentrations of immunoglobulin G, TP and the $\gamma$ globulin electrophoretic fraction, as well as the enzymatic activities of GGT and ALP. This was done in order to explore the possibility of using changes in activities of these enzymes as indirect indicators of adequate humoral immunity and/ or failure of immune passive transfer in lambs. Pearson correlation was performed between variable of four groups of age during the first 30 days of life. Blood samples (191) from lambs from 21 different farms in Araçatuba region- São Paulo. The following tests were perfomed: radial immunodiffusion, spectrophotometry and electrophoresis to stain the amount of IgG, TP and $\gamma$ globulin, respectively. GGT and ALP values were determinate using commercial kits. There was a statistically significant correlation between ALP and GGT. The same correlation was observed from TP, IgG and GGT. A positive $\gamma$ globulin correlation was found between GGT, IgG and TP. ALP activity cannot be used as an indicator of immune passive transfer.
\end{abstract}

Keywords: Alkaline phosphatase. Gamma glutamyl transferase. Immunoglobulin G. Total protein. $\gamma$ globulin.

\section{Introdução}

Os cordeiros adquirem proteção imunológica exclusivamente após o nascimento, através do colostro, em virtude do tipo de placenta que na ovelha é sindesmocorial ${ }^{1}$. Este processo, denominado de transferência de imunidade passiva, é de extrema importância para a proteção neonatal ${ }^{2}$.
O período crítico para os cordeiros são os primeiros dias pós-nascimento, quando estes mamam colostro

Correspondência para:

Francisco Leydson Formiga Feitosa

Rua Clóvis Pestana, 793, 16050-680 Araçatuba- SP

leydsonf@fmva.unesp.br

Recebido: $19 / 08 / 2008$

Aprovado: 07/01/2010 
insuficiente ou de baixa qualidade 3 , ocasionando "falha de transferência de imunidade passiva"4.

Muitos são os métodos utilizados para se determinar as concentrações séricas de imunoglobulinas em animais neonatos, e dentre estes, inclui-se a quantificação direta de imunoglobulina G (IgG) por imunodifusão radial $^{5}$. Os valores limítrofes entre hipogamaglobulinemia e concentrações normais de IgG em cordeiros ainda não foram completamente definidos. Na clínica, valores séricos de IgG entre 2000 e 3000 mg/dL, em animais com um a dois dias de idade, são aceitos como normais ${ }^{6}$.

A mensuração da proteína total (PT) no soro sanguíneo pode ser utilizada como método de avaliação indireta de IgG, associando-a à concentração total de globulinas ${ }^{5}$, sendo o seu valor, antes da ingestão de colostro, ao redor de 6,6 g/dL, e de $8,8 \mathrm{~g} /$ $\mathrm{dL}$, após a ingestão ter ocorrido ${ }^{7}$, decrescendo para $7,6 \mathrm{~g} / \mathrm{dL}$, às $48 \mathrm{~h}$ de vida ${ }^{8}$.

Em neonatos ruminantes, a atividade das enzimas gamaglutamiltransferase (GGT) e a fosfatase alcalina (ALP) no soro sanguíneo pode ser utilizada como método de avaliação da transferência de imunidade passiva ${ }^{9}$, pois a absorção intestinal não é seletiva em ruminantes neonatais ${ }^{10}$.

Os objetivos deste estudo visaram determinar as concentrações séricas de imunoglobulina G, PT e de sua fração gamaglobulina, e as atividades séricas das enzimas GGT e ALP, visando o diagnóstico de transferência de imunidade passiva em cordeiros com até 30 dias de idade, bem como estabelecer a correlação entre as variáveis nas diferentes faixas etárias e em quais grupos de estudo esta associação ocorre de forma mais evidente. Avaliar se as atividades séricas das enzimas GGT e ALP podem ser utilizadas indiretamente como indicadoras de adequado nível de proteção humoral e/ou como falha de transferência de imunidade passiva em cordeiros.

\section{Material e Método}

Foram coletadas amostras de sangue de 191 cordeiros saudáveis, com até 30 dias de vida, em 21 propriedades da região de Araçatuba - São Paulo. Os animais eram mantidos sob os regimes de criação intensiva (quatro propriedades), semi-intensiva (oito propriedades) e extensiva (nove propriedades).

Estes animais foram distribuídos aleatoriamente em quatro grupos, de acordo com a faixa etária, a saber: G1 0-7 dias de vida $(\mathrm{n}=50)$; G2 8-15 dias ( $\mathrm{n}=50)$; G3 16-22 dias $(\mathrm{n}=50)$ e G4 23-30 dias $(\mathrm{n}=41)$, sem distinção ao sexo, à raça e histórico de ingestão de colostro.

As coletas de sangue foram realizadas por punção da veia jugular, sendo este centrifugado e congelado imediatamente a $-20{ }^{\circ} \mathrm{C}$, até o momento de seu processamento.

Em todas as amostras coletadas, foram mensuradas as atividades séricas de GGT seguindo a metodologia de Szasz ${ }^{11}$, e de ALP, segundo as recomendações de McComb, Bower e Upretti ${ }^{12}$ com o uso de analisador bioquímico automático (Biosystems BTS 370 - Automatic Analyser), utilizando-se kits comerciais (GGT Labtest, Cod. 105 e ALP, Labtest, Cód. 40).

Para a quantificação da IgG no soro sanguíneo, foi realizado o teste de imunodifusão radial por meio do Vet-Rid Kit para ovinos (Bethyt, Cód. R50-100), em 22 animais pertencentes a cada um dos quatro grupos de idade, utilizando-se a metodologia empregada por Fahey e McKelvey ${ }^{13}$.

A concentração serica de PT foi determinada pelo método de biureto preconizado por Gornall, Bardawill e David ${ }^{14}$, utilizando-se, um espectrofotômetro digital SB-190, marca CELM, em 26 animais de G1, 42 animais de G2, 40 animais de G3 e 36 animais de G4. A redução no número de animais para esta análise deveu-se ao fato de a sua realização ter sido feita em laboratório externo. Efetuou-se a migração eletrofo- 
rética para separação das frações proteicas do soro sanguíneo dos animais que constituíram os grupos experimentais segundo as técnicas descritas por Friedman ${ }^{15}$ e Kremers, Briere e Batasakis ${ }^{16}$, utilizando fitas de acetato de celulose (Cellogel) de 2,5x14,0 $\mathrm{cm}$. A leitura e interpretação do fracionamento eletroforético foram realizadas em densitômetro para eletroforese (Quickscan 2000, Helena Laboratories), e por programa computacional (Quickscan 2000, Helena Laboratories), com marcação automática das diferentes frações proteicas.

A análise estatística foi realizada pelo Teste de Kruskal-Wallis e teste de comparações múltiplas de Dunn nas diferentes idades, para as diferentes variáveis (PT, fração $\gamma$-globulina, GGT, ALP e IgG). O coeficiente de correlação de Spearman foi utilizado para avaliar, dentro de cada grupo de idade, a associação entre as diferentes variáveis. As estatísticas foram consideradas significantes quando $\mathrm{p}<0,05$ e efetuada empregando-se o programa SAS (Statistical Analysis System $)^{17}$.

\section{Resultados e Discussão}

Não houve diferença estatística significativa entre os grupos de idade em relação à PT (Tabela 1). Ao analisar os valores desta variável, é possível observar que, em G1, nove (34\%) dos 26 cordeiros apresentaram teor sérico de PT menor que $5,0 \mathrm{~g} / \mathrm{dL}$, valor considerado por Radostits et al. ${ }^{1}$ como indicador de FTIP.
Nos animais do G3, apenas três dos 40 cordeiros analisados apresentaram valor sérico de PT menor que 5,0 g/dL, indicando diminuição do número total de animais com hipoproteinemia em relação ao dos animais do G2 (10/42). Em contrapartida, o número de animais com PT sérica menor que 5,0 g/dL elevou-se para dez (10/36) no G4, ocasionado, possivelmente, pela ocorrência de parasitose, enfermidade comum em cordeiros com esta faixa de idade, e/ ou pela degradação das imunoglobulinas adquiridas do colostro durante a fase neonatal e sua combinação com antígenos, faixa etária em que o sistema imune ainda não possui suficiente competência para produzir e manter-se em níveis elevados ${ }^{1}$. Esta hipótese é comprovada pela concomitante diminuição dos níveis de gamaglobulinas e de IgG, no mesmo período (Tabela 1).

Em todos os grupos houve forte correlação estatística positiva entre as variáveis PT e GGT (Tabela 2), ocorrência explicada pelo fato destas macromoléculas serem absorvidas logo após a ingestão do colostro, durante a fase de maior permeabilidade intestinal neonatal.

Como as IgGs constituem a maior parte da fração proteica gamaglobulina ${ }^{18}$ observou-se em G1, G2 e G3, correlação estatística positiva entre os valores de PT e às concentrações séricas de IgG, e destas, com a fração gamaglobulina (Tabela 2).

A análise dos teores da fração gamaglobulina no soro sanguíneo de cordeiros, ao longo dos 30 dias de vida, permitiu a observação de que os valores diferiram estatisticamente entre os grupos G1 a G4

Tabela 1 - Demonstração estatística através da Média $(\overline{\mathrm{X}})$, desvio-padrão (s) e mediana (Md) das concentrações séricas $(\mathrm{g} / \mathrm{dL})$ de proteína total e $\gamma$-Globulina de ovinos, segundo os grupos de idade - Araçatuba 2007

\begin{tabular}{|c|c|c|c|c|}
\hline \multirow{2}{*}{ Grupo } & \multicolumn{2}{|c|}{$\mathrm{PT}$} & \multicolumn{2}{|c|}{$\gamma$-Globulina } \\
\hline & $\overline{\mathrm{X}} \pm \mathrm{s}$ & Md & $\bar{X} \pm s$ & Md \\
\hline $\mathrm{G} 1(\mathrm{n}=26)$ & $5,56 \pm 1,06$ & $5,60 \mathrm{a}$ & $1,38 \pm 0,85$ & $1,32 \mathrm{a}$ \\
\hline $\mathrm{G} 2(\mathrm{n}=42)$ & $5,64 \pm 0,74$ & $5,85 \mathrm{a}$ & $1,01 \pm 0,42$ & $1,00 \mathrm{ab}$ \\
\hline $\mathrm{G} 3(\mathrm{n}=40)$ & $5,68 \pm 0,66$ & $5,60 \mathrm{a}$ & $1,08 \pm 0,41$ & $1,01 \mathrm{ab}$ \\
\hline $\mathrm{G} 4(\mathrm{n}=36)$ & $5,36 \pm 0,76$ & $5,40 \mathrm{a}$ & $0,88 \pm 0,36$ & $0,84 \mathrm{~b}$ \\
\hline
\end{tabular}

Medianas seguidas de mesma letra, na coluna, não diferem entre si ( $\mathrm{p}>0,05)$ pelo teste de Kruskal-Wallis e de comparações múltiplas de Dunn; $\mathrm{G} 1=0-7$ dias de vida, $\mathrm{G} 2=8-15$ dias, $\mathrm{G} 3=16-22$ dias, $\mathrm{G} 4=23-30$ dias 
Tabela 2 - Coeficiente de correlação de Spearman entre os valores das variáveis GGT, IgG, PT, $\gamma$ Globulina e FA, segundo os grupos de idade - Araçatuba - 2007

\begin{tabular}{|c|c|c|c|c|c|c|}
\hline \multirow{2}{*}{ Grupo } & \multirow{2}{*}{ Variável } & \multicolumn{5}{|c|}{ Variável } \\
\hline & & GGT & $\operatorname{IgG}$ & PT & $\gamma$ Globulina & FA \\
\hline \multirow{5}{*}{ G1 } & GGT & 1 & 0,341 & $0,499^{*}$ & $0,644^{*}$ & $0,315^{*}$ \\
\hline & $\operatorname{IgG}$ & & 1 & $0,565^{*}$ & $0,706^{*}$ & 0,072 \\
\hline & PT & & & 1 & $0,895^{*}$ & $-0,103$ \\
\hline & $\gamma$ Globulina & & & & 1 & $-0,203$ \\
\hline & FA & & & & & 1 \\
\hline \multirow{5}{*}{ G2 } & GGT & 1 & $0,542^{*}$ & $0,459^{*}$ & $0,548^{*}$ & $0,375^{*}$ \\
\hline & $\operatorname{IgG}$ & & 1 & $0,825^{*}$ & $0,809^{*}$ & 0,265 \\
\hline & $\mathrm{PT}$ & & & 1 & $0,884^{*}$ & 0,254 \\
\hline & $\gamma$ Globulina & & & & 1 & 0,208 \\
\hline & FA & & & & & 1 \\
\hline \multirow{5}{*}{ G3 } & GGT & 1 & 0,322 & $0,594^{*}$ & $0,647^{*}$ & $0,349^{*}$ \\
\hline & $\operatorname{IgG}$ & & 1 & $0,480^{*}$ & $0,473^{*}$ & 0,288 \\
\hline & $\mathrm{PT}$ & & & 1 & $0,756^{*}$ & 0,220 \\
\hline & $\gamma$ Globulina & & & & 1 & 0,056 \\
\hline & FA & & & & & 1 \\
\hline \multirow{5}{*}{ G4 } & GGT & 1 & 0,232 & $0,608^{*}$ & $0,609^{*}$ & 0,272 \\
\hline & $\operatorname{IgG}$ & & 1 & 0,208 & 0,332 & $-0,176$ \\
\hline & $\mathrm{PT}$ & & & 1 & $0,837^{\star}$ & 0,093 \\
\hline & $\gamma$ Globulina & & & & 1 & 0,056 \\
\hline & $\mathrm{FA}$ & & & & & 1 \\
\hline
\end{tabular}

${ }^{*} \mathrm{p}<0,05 ; \mathrm{G} 1=0-7$ dias de vida, $\mathrm{G} 2=8-15$ dias, $\mathrm{G} 3=16-22$ dias, $\mathrm{G} 4=23-30$ dias; GGT = Gamaglutamiltransferase; IgG= Imunoglobulina $\mathrm{G} ; \mathrm{PT}=$ Proteina Total; FA= Fosfatase Alcalina

(Tabela 1), sendo maiores nos animais mais jovens, devido à absorção de globulinas presentes no colostro $^{19}$, e menores nos animais mais velhos, em decorrência da degradação proteica após a cessação da ingestão de colostro, por ser a meia vida plasmática da IgG de 20 dias, aproximadamente ${ }^{20}$.

Cordeiros com concentrações séricas iguais ou superiores a $0,5 \mathrm{~g} / \mathrm{dL}$ de gamaglobulina, a 24 horas de vida, possuem maiores chances de sobreviver ao período pós-natal ${ }^{18}$. Apesar de os valores de gamaglobulina terem sido inferiores ao recomendado pelo autor acima descrito em um dos 26 cordeiros do G1; em seis (6/42) animais do G2; em dois (2/40) cordeiros do G3; e, em quatro (4/36) animais, do G4, não se observou, quando das colheitas das amostras, qualquer sintoma e/ou indício de enfermidade em nenhum cordeiro utilizado neste estudo.

Não houve diferença estatística significativa entre os grupos para IgG devido ao valor elevado desta classe de imunoglobulina no soro sanguíneo dos cordeiros. Contudo, notou-se redução gradativa do primeiro para o quarto grupo de idade, sendo o valor, em G1, quatro vezes maior que em G4 (Tabela 3).

Como demonstrado na tabela 4, houve diferença estatística nas atividades de GGT nos grupos 1, 2 e 4, sendo ainda mais evidente entre os animais do G1

Tabela 3 - Demonstração estatística dos valores mínimos (Min), máximos (Max) e medianas (Md) das concentrações sericas de IgG (mg/dL), segundo os grupos de idade - Araçatuba - 2007

\begin{tabular}{cccc}
\hline \multirow{2}{*}{ Grupo } & & IgG & Md \\
\cline { 2 - 4 } & Min & Max & $>1000 \mathrm{a}$ \\
G1(n=22) & 510 & $>1000$ & $>1000 \mathrm{a}$ \\
G2(n=22) & 248 & $>1000$ & $>1000 \mathrm{a}$ \\
G3(n=22) & 320 & $>1000$ & $885 \mathrm{a}$ \\
G4(n=22) & 135 & $>1000$ & \\
\hline
\end{tabular}

Medianas seguidas de mesma letra, na coluna, não diferem entre si $(\mathrm{p}>0,05)$ pelo teste de Kruskal-Wallis e comparações múltiplas de Dunn; $\mathrm{G} 1=0-7$ dias de vida, $\mathrm{G} 2=8-15$ dias, $\mathrm{G} 3=16-22$ dias, $\mathrm{G} 4=23-30$ dias; $\mathrm{IgG}=$ Imunoglobulina $\mathrm{G}$ 
Tabela 4 - Demonstração estatística da Média $(\overline{\mathrm{X}})$, desvio-padrão (s) e mediana $(\mathrm{Md})$ da atividade sérica (UI/L) de gamaglutamiltransferase e ALP, segundo os grupos de idade - Araçatuba - 2007

\begin{tabular}{|c|c|c|c|c|}
\hline \multirow{2}{*}{ Grupo } & \multicolumn{2}{|c|}{ GGT } & \multicolumn{2}{|c|}{ ALP } \\
\hline & $\overline{\mathrm{X}} \pm \mathrm{s}$ & Md & $\overline{\mathrm{X}} \pm \mathrm{s}$ & Md \\
\hline $\mathrm{G} 1(\mathrm{n}=191)$ & $733,50 \pm 1827,16$ & $203,65 \mathrm{a}$ & $868,53 \pm 1580,95$ & $659,25 \mathrm{a}$ \\
\hline $\mathrm{G} 2(\mathrm{n}=191)$ & $161,94 \pm 131,72$ & $109,50 \mathrm{~b}$ & $592,50 \pm 280,53$ & $572,15 \mathrm{a}$ \\
\hline $\mathrm{G} 3(\mathrm{n}=191)$ & $129,62 \pm 138,80$ & $85,90 \mathrm{bc}$ & $609,17 \pm 327,52$ & $584,55 \mathrm{a}$ \\
\hline $\mathrm{G} 4(\mathrm{n}=191)$ & $93,35 \pm 82,31$ & $69,99 \mathrm{c}$ & $402,67 \pm 210,63$ & $373,10 \mathrm{~b}$ \\
\hline
\end{tabular}

Medianas seguidas de mesma letra, na coluna, não diferem entre si ( $\mathrm{p}>0,05)$ pelo teste de Kruskal-Wallis e comparações múltiplas de Dunn; G1= 0-7 dias de vida, G2= 8-15 dias, G3= 16-22 dias, G4= 23-30 dias; GGT = Gamaglutamiltransferase; FA= Fosfatase Alcalina

e do G4, já que a atividade sérica desta enzima encontrava-se, em média, cerca de oito vezes menor nos animais de idade mais avançada, devido à degradação e/ou à diminuição da absorção enzimática, durante os primeiros 30 dias de vida ${ }^{21}$.

Constatou-se correlação estatística entre a atividade enzimática sérica de GGT e os níveis de IgG nos soros sanguíneos de animais que possuíam entre oito a 15 dias de idade (Tabela 2), demonstrando que a GGT pode ser utilizada como indicadora indireta de falha de transferência de imunidade em animais desta faixa etária, discordando dos achados de Maden et $a .^{5}$, que evidenciaram, em cordeiros, forte correlação entre estas duas variáveis, somente até os três primeiros dias de vida.

Não foi observada correlação estatística significativa entre a enzima ALP e as concentrações de IgG, PT

\section{Referências}

1.RADOSTITS, O. M.; GAY, C. C.; HINCHCLIFF, K.W.; CONSTABLE P. E. Veterinary medicine. a textbook of the diseases of cattle, sheep, pigs, goats and horses. 10.ed. London: Saunders, 2007. 2156 p.

2.CAMPBELL, S. G.; SIEGEL, M. J.; KNOWLTON, B. J. Sheep immunoglobulin and their transmission to the neonatal lamb. New Zealand Veterinary Journal, v. 25, p. 361-365, 1977.

3.ZARRILLI, A.; MICERA, E.; LACARPIA, N.; LOMBARDI, P.; PERO, M. E.; PELAGALLI, A.; D'ANGELO, D.; MATTIA, M.; AVALLONE, L. Evaluation of ewe colostrum quality by estimation of enzyme activity levels. Revue Medicine Veterinaire, v. 154, n. 8/9, p. 521-523, 2003.

4.QUIGLEY, J. D.; DREWRY, J. J. Nutrient and immunity transfer from cow to calf pre and postcalving. Journal of Dairy Science. v. 81, p. 2779-2790, 1998. e $\gamma$-globulina, em cordeiros com até 30 dias de idade (Tabela 2). Constatação semelhante foi verificada por Britti et al. ${ }^{22}$ que mencionaram discreta correlação entre a atividade de ALP e a concentração de IgG sérica no primeiro dia de vida, sendo que, em cordeiros com esta mesma faixa etária, o aumento da referida enzima no soro sanguíneo não refletiu, proporcionalmente e quantitativamente, sua atividade na secreção colostral de suas mães.

\section{Conclusões}

As concentrações séricas de IgG e de proteína total não se alteraram em cordeiros ao longo dos 30 dias de vida. A atividade da GGT pode ser utilizada como indicadora indireta de transferência de imunidade passiva em ovinos, não tendo, a atividade sérica de ALP, a mesma indicação.

5.MADEN, M.; ALTUNOK, V.; BIRDANE, F. M. B.; ASLAN, V.; NIZAMLIOGLU, M. Blood and colostrums/milk serum gamma-glutamytransferase activity as a predictor of passive transfer status in lambs. Journal of Veterinary Medidine Series B, v. 50, n. 3, p. 128-137, 2003

6.GILBERT, R. P.; GASKINS, C. T.; HILLERS, J. K.; PARKER, C. F.; MCGUIRE, T. C. Genetic and environmental factors affecting immunoglobulin G1 concentration in ewe colostrums and lamb serum. Journal of Animal Science, v. 66, n. 4, p. 855-863, 1988.

7.CZARNECKI, A.; GLUSZAK, A.; LAW, K. R. W.; RADYMSKAWAWRZYNIAK, K.; RYBKA, A.; STUDZINSKI, T. Changes in erythrocytes, leukocytes and immunoglobulins in Polish lowland long wool lambs during the postnatal period. Medycyna Weterynaryina, v. 47, n. 2, p. 90-92, 1991. 
8.AHAMAD, R.; KHAN, A.; JAVED, M. T. J.; HUSSAIN, I. The level of immunoglobulins in relation to neonatal lamb mortality in Pak-Karakul sheep. Veterinarski Arhiv, v. 70, n. 3, p. 129-139, 2000.

9.BRAUN, J. P.; RICO, A. G.; BERNARD, P.; THOUVENOT, J. P.; BONNEFIS, M. J. Tissue and blood distribution of gammaglutamyl transferase in the lamb and in the ewe. Research in Veterinary Science, v. 25, n. 1, p. 25-37, 1978.

10.WEAVER, D. M.; TYLER, J. W.; VANMETRE, D. C.; HOSTETLER, D. E.; BARRINGTON, G. M. Passive transfer of colostral immunoglobulins in calves. Journal of Veterinary Internal Medicine, v. 14, n. 6, p. 569-577, 2000.

11.SZASZ, G. A kinetic photometric method for serum gamaglutamil transpeptidase, Clinical Chemistry, v. 15, p. 124-136, 1969.

12.MCCOMB, R. B.; BOWER, G. N.; UPRETTI, A. 4-nitrophenyl phosphatase characterization of high-purity materials for measuring alkaline. Clinical Chemistry, v. 27, n. 1, p. 135-141, 1981.

13.FAHEY, J. L.; MCKELVEY, E. M. Quantitative determination of serum immunoglobulins in antibody agar plates Journal of Immunology, v. 94, p. 84-90, 1965.

14.GORNALL，A. G.; BARDAWILL，C. J.; DAVID, M. M. Determination of serum protein by means of biuret reaction. Journal of Biological Chemistry, v. 177, n. 2, p. 751-766, 1949.

15.FRIEDMAN, H. S. A standardized procedure for serum protein electrophoresis on cellulose acetate membrane strips. Clinica Chimica Acta, v. 6, n. 6, p. 775-781, 1961.

16.KREMERS, B.; BRIERE, R.; BATASAKIS, J. G. Reflectance densitometry of cellulose acetate protein electrophoresis. American Journal of Medical Technology, v. 33, n. 1, p. 28 34, 1967.

17.STATISTICAL ANALYSIS SYSTEM. SAS user's guide: statistics. Versão 8. Cary: SAS Institute, 1999.

18. TIZARD, I. R. Imunologia veterinária. 5. ed. São Paulo: Roca, 1998. $544 \mathrm{p}$.

19.LEVIEUX, D.; MORGAN F.; GENEIX, N.; MASLE, I. Caprine immunoglobulin G, $\beta$-lactoglobulin, $\alpha$-lactalbumin and serum albumin in colostrum and milk during the early post partum period. Journal of Dairy Research, v. 69, n. 3, p. 391-399, 2002.

20.LOGAN, E. F.; PENHALE, W. J.; JONES, R. A. Changes inserum imunoglobulins of colostrum fed calves during the first twelve weeks postpartum. Research Veterinary Science, v. 14, n. 3, p. 394-397, 1972.

21.PAULI, J. V. Colostral transfer of gamma glutamyl transferase in lambs. New Zealand Veterinary Journal, v. 31, n. 9, p. 150$151,1983$.

22.BRITTI, D.; MASSIMINI, G.; PELI, A.; LUCIANI, A.; BOARI, A. Evaluation of serum enzyme activities as predictors of passive transfer status in lamb. Journal of American Veterinary Medical Association, v. 226, n. 6, p. 951-955, 2005. 